\title{
DIRETRIZES PARA O USO DE CORES EM UM PROJETO RESIDENCIAL DEDICADO A PACIENTES COM DOENÇA DE ALZHEIMER
}

\author{
DINIZ, Danyel Magnus de Oliveira (1); \\ MCAULIFFE, Marisha (2)
}

(1) Universidade de Fortaleza, Estudante de Arquitetura e Urbanismo

e-mail: danyel.diniz@gmail.com

(2) Gurukul School of Design, Reitora e Diretora de Planejamento Estratégico e

Comunicação

e-mail: marishamcauliffe@gmail.com

\begin{abstract}
RESUMO
Este artigo analisa estudos já realizados sobre a influência da cor do espaço na vida diária de pacientes com doença de Alzheimer. Cinco estudos foram revisados recorrendo a perguntas-chave que criaram o fundamento desta análise. Posteriormente, este trabalho demonstra uma utilização prática dos princípios por trás do design de cores, a planta baixa de uma residência previamente projetada. Pesquisas indicam que cores afetam os pacientes para além da forma como afetam o restante da população; entretanto, alguns autores reafirmam que cores não devem ditar por si sós um design voltado para estes pacientes.
\end{abstract}

Palavras chave: Alzheimer; PA (pacientes com doença de Alzheimer); cor, ambiente e projeto.

\begin{abstract}
This article analyzes previous research that studied the influence of the environment's color on the daily life of Alzheimer's patients. Five studies have been revised using the same key questions, which created the analysis' base. Furthermore, this study demonstrates a practical use for the principals behind the color design, utilizing a home's previously designed floor plan. Research indicates that color affects Alzheimer's patients beyond the way it does to the rest of the population; however, authors reaffirm color should not solely dictate a design dedicated to these patients.
\end{abstract}

Keywords: Alzheimer; AP (Alzheimer's patient); color, environment and design.

\section{INTRODUÇÃO}

Este trabalho foi realizado com o apoio do CNPq, Conselho Nacional de Desenvolvimento Científico e Tecnológico do governo brasileiro.

De acordo com a OMS (2017), Organização Mundial de Saúde, 47 milhões de pessoas são mundialmente diagnosticadas com algum tipo de demência; e este número aumentará para 132 milhões em 2050. É sabido que a doença de Alzheimer ataca diversas pessoas especialmente na terceira idade, sendo a doença mais comum durante este estágio da vida abrangendo de 60 a $70 \%$ de todos os casos de demência, como indica a OMS (2017) - e sem cura conhecida (PASCALE, 2002). Com a população idosa aumentando em vários países ao redor do mundo, pesquisas sobre diferentes condições - físicas, psicológicas, sociais, etc. - relacionadas a esta fase da vida vem se 
tornando mais relevantes e frequentes, com o objetivo não apenas de compreender melhor tais condições, mas também de descobrir soluções que elevem a qualidade de vida de pacientes (FLEMING; CROOKES; SUM, 2008). O Brasil, por exemplo, segundo dados também da OMS, como citado por Sousa e Maia (2014), em 2025 atingirá a sexta posição de país com o maior número de pessoas idosas no mundo. De acordo com a mesma organização, em 2050 a população mundial com 60 anos ou mais será de 2 bilhões (BEARD, 2014). Com isso, estudos têm sido feitos relacionados com a forma que o ambiente - em seus diferentes níveis, como ergonomia, iluminação, cor e materiais afeta estes pacientes (PASCALE, 2002; FLEMING, CROOKES, SUM, 2008).

Quando se menciona "tratamento", muitos pacientes são enviados para casas de cuidados especializados devido à falta de tempo e/ou capacidade da família em cuidar dos pacientes por si sós. Entretanto, estudos mostram que permitir ao paciente continuar a viver em seu lar pode contribuir com seu bem-estar e reduzir o ritmo do processo degenerativo.

Este presente artigo, portanto, busca compreender como um design baseado no estudo de cores pode influenciar a rotina de um PA (paciente de Alzheimer) e contribuir com uma melhor qualidade de vida, especificamente em um ambiente residencial. Alguns estudos anteriores foram analisados com perguntas-chave tomadas como guia. Assim, este artigo se inicia com um rápido entendimento do que é a doença do Alzheimer e as diferenças entre as necessidades dos pacientes acometidos dessa condição e as necessidades regulares da população idosa como um todo. Após discutir sobre a importância do tema em questão, adentra-se no assunto de como os espaços construídos podem impactar um PA, seguindo com a questão principal e sua resposta sobre como um design voltado à cor influencia a vida diária destes pacientes.

Finalmente, após reunir as informações necessárias e os princípios do design de cores, uma sugestão prática de design é feita - utilizando uma planta baixa prévia a este estudo e também desenvolvida para se adequar à rotina de um PA - para um melhor entendimento e visualização destes princípios (SOUSA; MAIA, 2014).

\section{REVISÃO LITERÁRIA}

\subsection{Clarke \& Alan}

Apresentando uma nova abordagem qualitativa para um tipo de pesquisa e foco que haviam sido previamente levantados, este trabalho buscou avaliar os impactos das cores em indivíduos, as associações emocionais feitas a elas, assim como a associação destas últimas com eventos, conceitos e seus significados mais gerais. A pesquisa tratou de forma diferente este tópico quando comparado a estudos anteriores, dando aos participantes da pesquisa liberdade em vários aspectos, como na escolha da "versão" - tonalidade, saturação - da cor em estudo que eles gostariam de utilizar, além de não restringir as respostas dos participantes a um conjunto de palavras preliminarmente escolhidas.

A pesquisa, entretanto, teve limitações. O número de participantes foi consideravelmente pequeno, todos estudavam na mesma universidade, faziam parte da mesma faixa etária e raça, e residiam no mesmo país. O estudo, assim, pode ter sido influenciado por estes fatores e a possibilidade do teste ser feito com uma amostra populacional maior e mais diversificada traria resultado mais sólidos. 


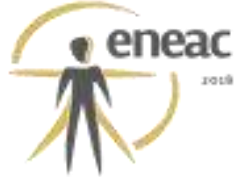

\subsection{Fleming, Crookes \& Sum}

O trabalho de Fleming, Crookes e Sum (2008) é também uma revisão literária que trata do processo projetual do ambiente construído para pacientes com doença de Alzheimer, trazendo um enfoque nas recomendações feitas pela Professora Mary Marshall do Dementia Services Development Centre, na Escócia. Estas diretrizes estão agora também disponibilizadas pela organização Alzheimer's Australia.

\subsection{McKeron}

Este trabalho volta-se para o entendimento das mudanças pelas quais o cérebro de um PA passa e como estas mudanças influenciam a vida do indivíduo. Seguidamente, explica a forma específica de cuidado requerido por estes pacientes em vários níveis: desde cuidados caseiros e o envolvimento da família no processo até cuidados profissionais e institucionais. Todo este estudo é utilizado como base para sugerir o tipo de design que deve ser mais apropriado para as necessidades destas pessoas, citando subáreas projetuais, avaliando estudos e propostas anteriores e, finalmente, apresentando sua própria proposta de projeto para uma tipologia residencial de clínica de cuidados para PAs.

É um artigo bem estruturado que alcança seu objetivo de propor um projeto arquitetônico. Por outro lado, a proposta de moradia é comunitária e institucional, e não de residência individual, que é o foco do nosso estudo. McKeron (2010) também não avança no tema de cores, focando na distribuição espacial do projeto.

\section{$2.4 \quad$ Pascale}

Este trabalho foi publicado como dissertação final do autor para a obtenção do título de Mestre em Engenharia de Produção. Contém uma abordagem teórica sobre a forma como o ambiente afeta a vida do paciente de Alzheimer, focando no seu potencial terapêutico. A dissertação concentra diversos assuntos que posteriormente culminam na base da análise central. Após uma explanação detalhada sobre a doença em si, o termo "ergonomia" e o que este representa, o estudo volta seu foco para fatores ambientais específicos e como eles influenciam indivíduos nestas condições.

O trabalho contém uma vasta abordagem de temas e discorre sobre numerosas formas de aplicação dos princípios ergonômicos no projeto de espaços para a população sênior e em especial para os pacientes de demências em suas mais diversas formas. Contudo, para a perspectiva deste presente artigo, que tem seu foco em cores e seus efeitos, a dissertação de Pascale (2002) apresenta informações reduzidas, voltando-se de forma mais eficaz ao projeto físico destes espaços.

\subsection{Sousa \& Maia}

O artigo é uma revisão bibliográfica com o escopo de descrever a contribuição dos principais aspectos de um ambiente interno para um paciente de Alzheimer. Além disso, o artigo expressa as várias maneiras e áreas nas quais o ambiente influencia a rotina de um PA e como este ambiente pode ser usado para facilitar suas vidas e retardar ao máximo possível o desenvolvimento da doença e de seus efeitos. Entretanto, como o próprio estudo menciona, poucas pesquisas foram feitas neste campo e as que foram realizadas nem sempre são de fácil acesso. Dessa forma, sendo uma revisão bibliográfica, possui limitações, não oferecendo profundidade nos conceitos e soluções - apesar de em grande número - apresentadas. 


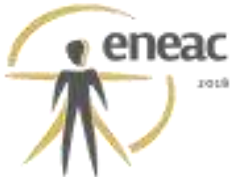

\section{PERGUNTAS-CHAVE}

\subsection{O que é a doença de Alzheimer?}

É uma doença neurodegenerativa que atinge a população idosa, mas que pode se iniciar mais cedo. Os sintomas eram antes entendidos como comuns e parte do processo de envelhecimento humano, mas estudos provaram tais conceitos como errôneos e mostraram que esta condição se trata de um dos vários tipos de demência e que, em muitos casos, pode vir associado a outras doenças.O Alzheimer não possui cura e é irreversível, porém medicamentos agora disponíveis são capazes de retardar o processo degenerativo e abrandar os sintomas (PASCALE, 2002). Os efeitos da doença são muitos e esta é seccionada em três estágios.

Os pacientes são inicialmente sujeitos, no primeiro estágio que dura de dois a quatro anos e precede o diagnóstico, a dificuldades em concluir tarefas simples, tomar decisões e lembrar de eventos recentes. Já no segundo estágio, sendo este o estágio mais longo, durando entre dois a até dez anos, os sintomas se tornam mais agressivos. O paciente sofre de problemas de coordenação motora, dificuldades de expressão e de lembrar dados mais sólidos e pessoas mais próximas como amigos e parentes, além de ocorrer distorções de realidade. Ao atingir o estágio final no qual os pacientes não reconhecem a si próprios, perdem o controle motor, a habilidade linguística e o controle fisiológico (Pascale, 2002).

\subsection{Quais são algumas das diferenças entre as necessidades de um paciente e o restante da população idosa?}

Não apenas pelo fato de que a população na terceira idade - aqui considerada como a alcançada aos 65 anos de acordo com o critério cronológico da ONU citado por Pascale (2002) - ter suas necessidades específicas quando comparada a população pertencente a outros estágios da vida, um paciente de Alzheimer, devido às consequências de sua condição, requer grande atenção e suporte. À medida que a doença se desenvolve, os pacientes se tornam mais dependentes do auxílio de terceiros para realizar atividades básicas como tomar banho, comer, trocar de roupa e até mesmo ir de um local para outro (PASCALE, 2002). A razão para este fato está não apenas na perda motora, muscular e de destreza, mas a perda de memória também faz com que o indivíduo esqueça como realizar tarefas diárias e onde locais, antes familiares, se encontram.

No processo de envelhecimento, outra área afetada da biologia humana é a visão. Estudos revelam que um indivíduo de 60 (sessenta) anos de idade captura apenas de 30 a 40\% da luz capturada por uma pessoa de 20 anos de idade (SOUSA; MAIA, 2014). Isso se deve às mudanças que ocorrem no sistema ocular humano, tais como perda na flexibilidade da retina que causa a diminuição do campo visual e da capacidade de ajuste ao escuro. Além disso, como o Alzheimer é uma condição que majoritariamente afeta a população idosa, pacientes não apenas precisam lidar com as alterações naturais de seus corpos, mas também com os efeitos da doença em si, como visão turva, dificuldades em perceber contrastes espaciais, movimento e cor. (SOUSA; MAIA, 2014).

\subsection{Por que esta pesquisa é relevante?}

A longevidade em diversos países está aumentando, e com isso o número de doenças degenerativas relacionadas a terceira idade, como o Alzheimer, também se eleva e atinge maiores porcentagens da população mundial (SOUSA; MAIA, 2014). De acordo com dados da OMS - Organização Mundial da Saúde - o número de idosos chegará a 2 bilhões em 
2050, Portanto, um estudo sobre como tornar a vida de um paciente de doença degenerativa melhor é de fundamental importância para o bem-estar destes indivíduos e de seus familiares e amigos. E isso é possível através de soluções simples e básicas de design. Assim, o número de pesquisas sobre os impactos do espaço e sua ergonomia na vida dos pacientes vem crescendo nos últimos anos (FLEMING; CROOKES; SUM, 2008).

Um lado positivo de ter pacientes sendo tratados em seus próprios lares é permitir que estejam rodeados de seus entes queridos (MCKERON, 2010). Esse tipo de ambiente pode trazer conforto ao paciente por ser capaz de reconhecer objetos pessoais e espaços familiares, auxiliando no funcionamento de suas mentes e memórias. Entretanto, McKeron (2010) também alerta sobre aspectos negativos no cuidado residencial. De forma geral, parentes não possuem as habilidades específicas requeridas ao cuidado de um indivíduo nestas condições delicadas, o que pode ocasionar em tratamento insuficiente além de frustrações, raiva e, em alguns casos, depressão nos parentes devido à experiência de ver seus entes queridos lentamente sucumbirem à doença.

\subsection{Qual a importância do espaço físico para um paciente de Alzheimer?}

Sintomas e efeitos colaterais não estão apenas relacionados à condição clínica em si do indivíduo, mas também às suas características pessoais e singulares, como personalidade, padrões comportamentais e biológicos e fatores ambientais (PASCALE, 2002). É por isso que o ambiente construído pode ter um maior impacto e influência em portadores de demência quando comparado a indivíduos alheios a essa condição. Um ambiente que não prover estímulos adequados pode desencadear comportamentos indesejados, como, por exemplo, expressões de raiva, frustração, angústia e tristeza (SOUSA; MAIA, 2014). Portanto, o tratamento correto deve conter um foco em criar uma rotina para o paciente que preserve suas capacidades ao máximo, nunca deixando de lado, porém, a importância da correta medicação e tratamento farmacológico.

Com estas informações em mente, o ambiente construído pode certamente facilitar a interação do paciente com seu entorno, compensar déficits cognitivos e reforçar habilidades remanescentes (PASCALE, 2002). Todos respondem de forma diferente ao espaço com que se interage e suas várias camadas - cor, luz, formas, som, etc. Um paciente de demência tem sua forma particular de perceber o espaço e interagir com ele. Um ambiente ergonomicamente bem projetado para um PA pode facilitar as tarefas diárias e tornar estes indivíduos mais independentes, elevando sua autoconfiança e bem-estar (PASCALE, 2002).

Um bom projeto luminotécnico, por exemplo, tem a possibilidade de contribuir com a segurança do paciente, criando caminhos e objetos mais visíveis e prevenindo estas pessoas de sentirem tonturas e desorientações por vezes ocasionadas por índices de iluminância e claridade elevados (SOUSA; MAIA, 2014). O estudo feito por Sousa e Maia cita Torrington, 2007, que afirma que portadores da demência do Alzheimer precisam de um sistema de iluminação que provê entre 300 a 700 lux com todas as superfícies dos ambientes bem iluminadas a fim de evitar sombras em superfícies irregulares que podem criar uma falsa sensação de profundidade. Superfícies reflexivas também podem desestabilizar o paciente e aumentar suas chances de fracasso em suas atividades rotineiras. O projeto deve sempre priorizar iluminação natural sobre artificial.

Um bom projeto luminotécnico pode gerar um ambiente mais familiar e residencial (PASCALE, 2002) e isso pode ser promovido ao permitir o acesso, tanto quanto possível, de luz natural em vez de artificial, ao criar mudanças graduais de níveis de iluminância entre diferentes áreas, prover luz focal em objetos específicos e relevantes a fim de trazer atenção a estes e, finalmente, ao aumentar a produção de cores provinda da fonte luz (PASCALE, 2002). 


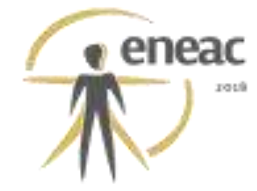

\subsection{Qual a influência da cor na vida de um paciente de Alzheimer?}

À medida em que um indivíduo envelhece, sua visão é comprometida - perda do senso de perspectiva, profundidade e distância assim como da habilidade de diferenciar cores somadas à redução da percepção de contrastes. Contudo, especialmente nos estágios iniciais da doença, um PA é ainda influenciado por cores semelhantemente ao restante da população, não existindo estudos que comprovem o contrário (SOUSA; MAIA, 2014). Dessa forma, a cor pode também auxiliar o paciente a sentir felicidade, contentamento, paz, recordar ambientes e suas funções.

A partir do momento em que o PA começa a ter perdas em sua memória e sentidos em geral, um uso eficiente de cores no ambiente pode também assessorar o paciente na distinção de áreas e espaços ao trazer foco àquilo que requer atenção e esconder locais e objetos que não é recomendado ao paciente ter acesso.

\subsection{Como um projeto com foco em cores pode contribuir para uma melhoria de vida dos pacientes com doença de Alzheimer?}

Apesar de estudos sugerirem que objetos são uma ferramenta que melhor especificam e definem espaços para um paciente de demência em comparação a cores e isso ter se tornado um princípio projetual (FLEMING; CROOKES; SUM, 2008), a cor também pode ainda ser utilizada para guiar, informar e auxiliar residentes dementes a achar objetos, áreas e a se localizarem, especialmente nos estágios mais iniciais da condição clínica.

Tanto os aspectos emocionais quanto físicos da cor estão agora sendo aplicados lado a lado com o campo médico para o tratamento de pacientes em geral (PASCALE, 2002). Para a população idosa, todavia, cores tem um impacto maior devido às já citadas alterações visuais ocasionadas pela idade (PASCALE, 2002). Cores frias se tornam menos perceptíveis e distinguíveis entre si; azul e violeta passam a se assemelhar ao cinza, e a percepção de profundidade e distância passa a ser uma tarefa árdua. Cores contrastantes colocadas em conjunto, especialmente quentes e claras como vermelho, são, assim, uma ferramenta de valor no projeto de espaços para a população idosa, pois ajudam os usuários a perceberem melhor o ambiente (PASCALE, 2002).

O mesmo estudo feito por Pascale (2002) expressa a relevância que as cores têm como ferramentas de sinalização, ajudando idosos na diferenciação, por exemplo, de seus quartos e dos quartos adjacentes. Entretanto, ao se tratar de PA, muitos autores, como ainda cita Pascale (2002), argumentam que a cor por si só não configura a melhor solução na distinção e caracterização de espaços, e requer a assessoria de outros elementos para a tarefa, como formas e sinalizações apropriadas (PASCALE, 2002).

\subsubsection{Identificação de Espaços}

Por vezes, um PA pode não identificar certas áreas pela forma como estão posicionadas, sua função ou mobiliário, sendo comum pacientes se perderem dentro de seus próprios lares ou utilizarem de forma equivocada determinados compartimentos (PASCALE, 2002). Portanto, cores podem desempenhar um papel de distinguir áreas para pacientes através do uso de diferentes matizes e tonalidades em diferentes espaços. Assim, o quarto pode não ser lembrado como o cômodo que contém a cama, mas como o que possui a porta amarela - priorizando sempre cores quentes nas identificações, pois estas são as mais facilmente percebidas. 


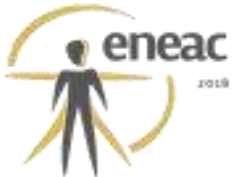

\subsubsection{Gerar Atenção}

O mesmo princípio pode ser empregado, se necessário, para chamar a atenção a certos objetos e traços do ambiente que sejam importantes ao cotidiano do paciente. O efeito pode ser criado através do uso de cores clara e saturadas que contrastem com o plano de fundo. Corrimãos, ao longo de paredes, principalmente de corredores e banheiros, podem ser melhor identificados quando pintados de uma cor contrastante à cor aplicada nas paredes - um corrimão vermelho em uma parede neutra, por exemplo (SOUSA; MAIA, 2014).

\subsubsection{Esconder Elementos}

A característica projetual citada acima, quando lançada mão de forma oposta, pode esconder objetos e espaços que não são recomendados ao paciente de Alzheimer ter acesso. Uma porta que leva a quartos que não sejam seguros ao indivíduo pode ser camuflada ao receber a mesma cor da parede na qual se insere, preferencialmente optando por tonalidades frias e pastéis mais difíceis de ser reconhecidas pelo paciente (SOUSA; MAIA, 2014).

\section{O USO PRÁTICO DE CORES NO PROJETO PARA PACIENTES DA DOENÇA DE ALZHEIMER}

Tendo enfim respondido as perguntas levantadas, o presente artigo apresentará neste item uma proposta de design de cores para uma residência também projetada com base nas necessidades de um PA através da aplicação prática das sugestões apresentadas anteriormente na análise e revisão literária. A planta baixa apresentada na Figura 1 foi adaptada de um layout previamente desenvolvido na Universidade de Stirling, na Escócia (SOUSA; MAIA, 2014). Foram aplicados nesta planta baixa os princípios de design de cores apresentados neste presente estudo.

Figura 1: Planta Baixa Residencial Adaptada

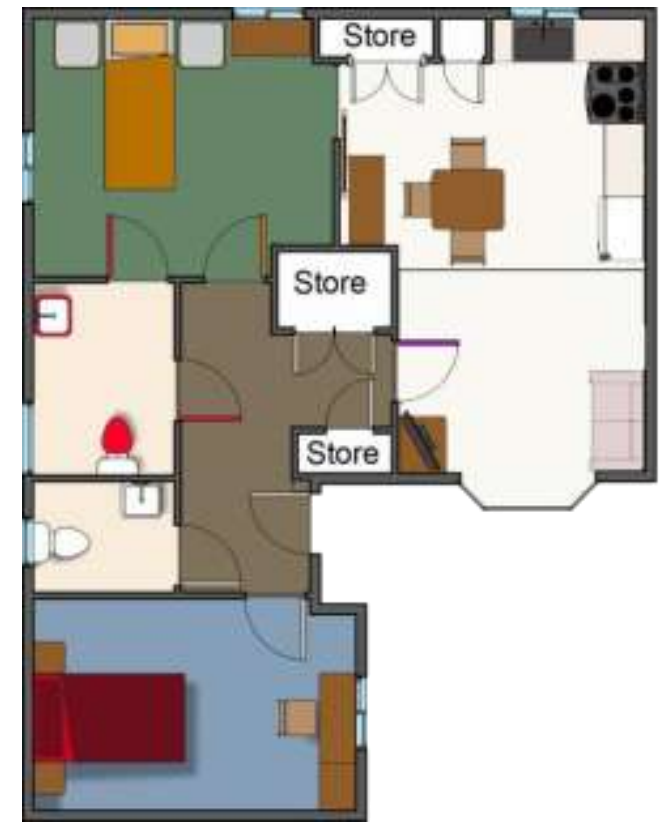

Fonte: Adaptada de layout de casa projetada para portadores de demência em Ayr, Escócia pelo Dementia Services Development Centre da Universidade de Stirling; citado por SOUSA, MAIA, 2014. 


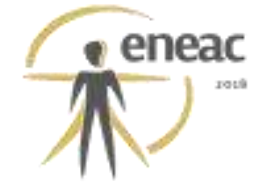

\subsection{Identificar Espaços}

Espaços que o paciente pode acessar e onde este passará mais tempo são identificados com menos esforço pelo uso de cores quentes, que são percebidas com mais facilidade, chamam atenção, sugerem mobilidade e ação (PASCALE, 2002). O banheiro utilizado pelo paciente tem suas portas pintadas de vermelho, como as Figuras 1 e 2 expõem, pois estudos sugerem o vermelho como a cor que mais demanda atenção e cria emoções fortes (CLARKE; COSTALL, 2008). Além disso, as referidas portas guiam o indivíduo a um cômodo no qual sua completa atenção é demandada.

Para o interior do quarto do paciente, utilizou-se o verde nas cortinas e carpete, juntamente com o laranja na cama (Figura 2). O verde gera sensações de conforto, paz, natureza quando tem tons oliva - e baixa ansiedade (CLARKE; COSTALL, 2008). Já o laranja não apenas chama a atenção (Pascale, 2002), como gera a sensação de pertencimento e calidez (CLARKE; COSTALL, 2008). O laranja também foi a cor empregada nas portas do quarto do paciente foram pintadas de laranja, como apresentado nas Figuras 1 e 4.

Apesar de ser uma cor calma que, no decorrer do processo de envelhecimento natural e degeneração pela doença se tornará possivelmente menos distinguível, o violeta foi empregado na porta entre o corredor e a sala de estar, apresentada nas Figuras 1 e 3. Esta passagem leva o paciente a ambientes que não requerem grande atenção e podem ser diferenciados por outros elementos como formas e itens decorativos e de uso. A cor violeta, apesar de ter tendências à classificação de "fria", no estudo realizado por Clarke e Costall (2008), não recebeu nenhuma referência quanto à sua temperatura pelos entrevistados.

O piso da cozinha e da sala de estar é o mesmo (Figuras 1, 3 e 4), com coloração branca e neutra, pois, como não existem limites físicos entre as duas áreas, uma mudança significativa na aparência do piso poderia resultar em perda de equilíbrio e orientação do paciente (PASCALE, 2002). A identificação da separação dos dois ambientes foi realizada nas paredes, em especial através do uso de um elemento de madeira com iluminação em fitas de LED embutidas, no limite entre os dois cômodos, como apresentado pela Figura 4.

\section{Figura 2: Perspectiva Interna em Modelagem 3D do Quarto do Paciente}

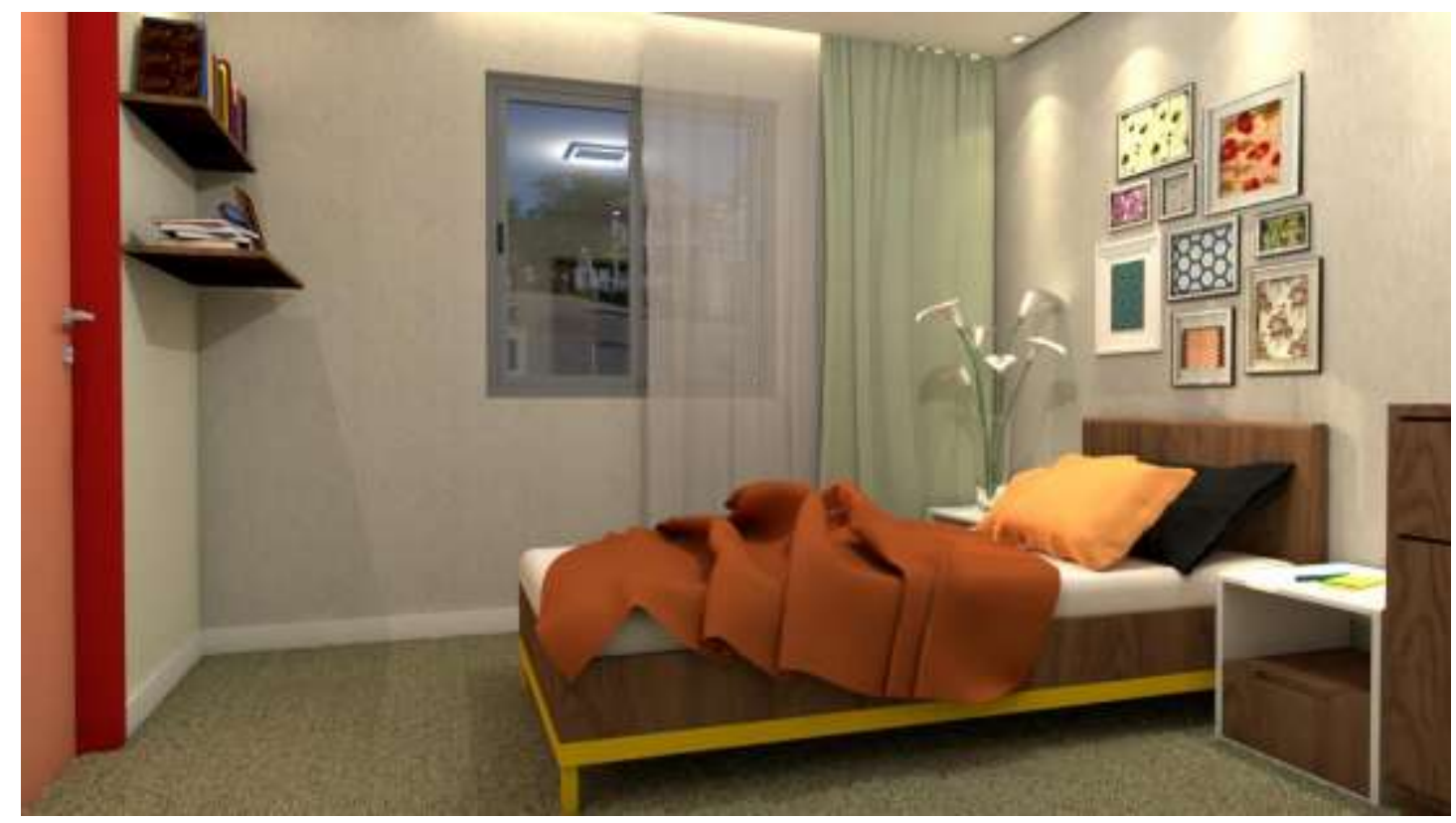

Fonte: Acervo pessoal do autor 


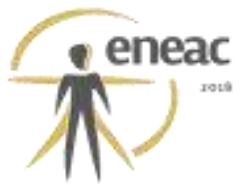

Figura 3: Perspectiva Interna em Modelagem 3D da Sala de Estar

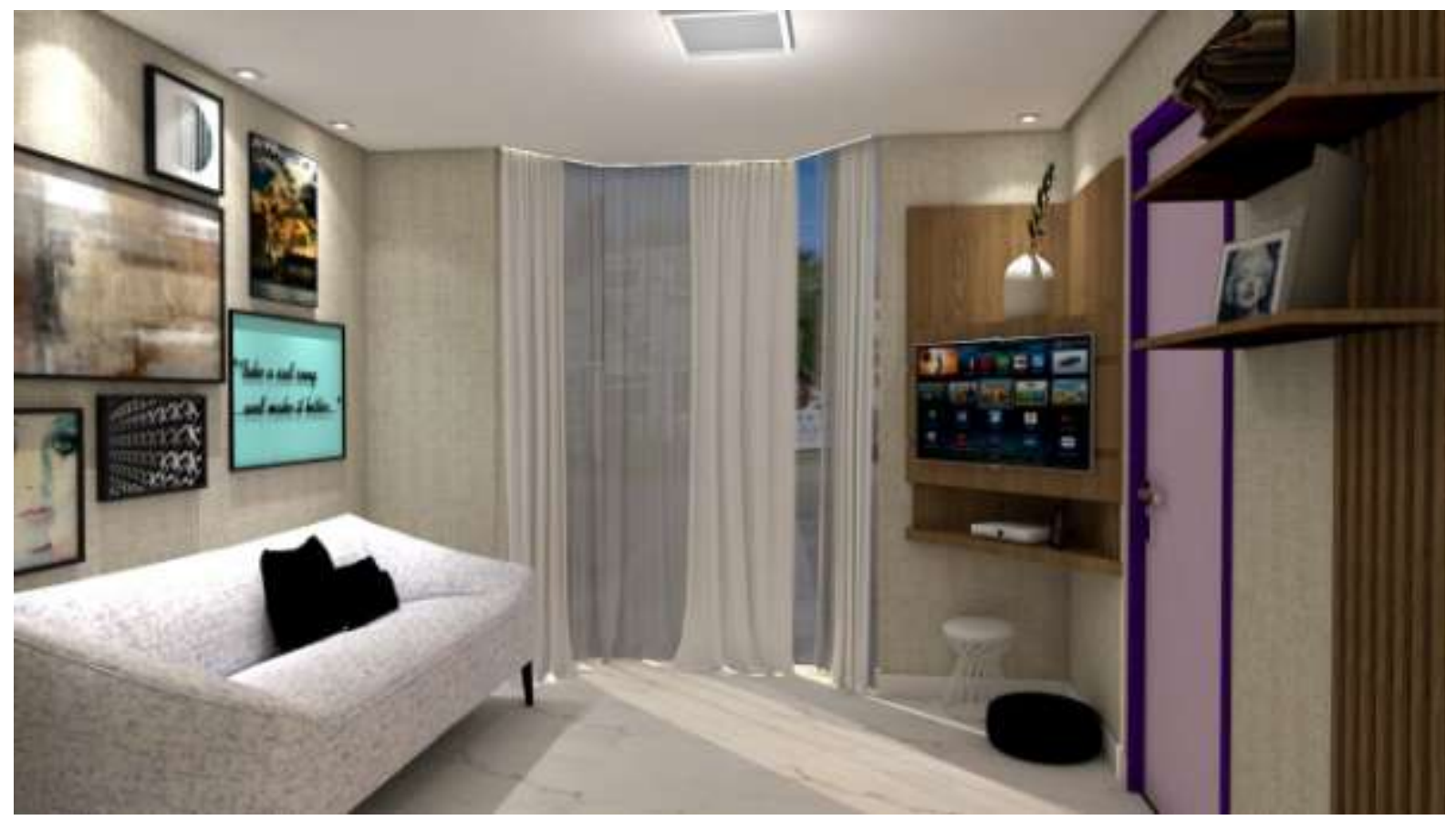

Fonte: Acervo pessoal do autor.

\subsection{Gerar Atenção}

Atenção a objetos frequentemente utilizados precisa ser gerada para prevenir equívocos de uso e déficits de percepção. A tampa e assento da privada, assim como as bordas da pia, foram destacados pela cor vermelha que foi designada para o banheiro utilizado pelo paciente (Figura 1). Isto foi feito para prevenir o mau uso das instalações assim como a possibilidade do paciente não as encontrar. A cor neutra aplicada no restante do cômodo também auxilia às peças serem identificadas (SOUSA; MAIA, 2014).

Já as bordas de certos mobiliários nos ambientes acessados pelo paciente foram destacadas pelo uso da cor amarela, quente e saturada (SOUSA; MAIA, 2014), como apresentado nas Figuras 2 e 4. Isto foi feito para que o paciente tenha uma melhor noção de seus arredores e evite machucar-se ao aproximar-se destes objetos.

\subsection{Esconder Elementos}

Apesar de projetada para um paciente da doença de Alzheimer, uma residência pode ainda assim conter objetos e espaços inadequados à interação com o paciente. Com isso, 0 acesso aos mesmos pode ser dificultado pelo emprego da mesma cor tanto nestes elementos quanto em seus arredores para que se mesclem ao restante do ambiente (SOUSA; MAIA, 2014).

O balcão da cozinha e as gavetas foram pintadas na mesma cor bege das paredes para que sejam camuflados e o acesso limitado. O princípio foi aplicado nas portas da despensa, como representado na Figura 4 abaixo, assim como em algumas portas do corredor central, tais como na porta de entrada principal da casa, na porta do segundo quarto e banheiro e nas áreas de depósito (Figura 1). $O$ fato de no corredor existirem outras aberturas significantemente destacadas torna as portas camufladas ainda menos perceptíveis pelo paciente. 


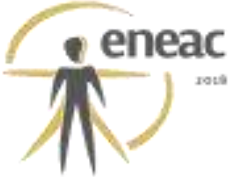

Figura 4: Perspectiva Interna em Modelagem 3D da Cozinha

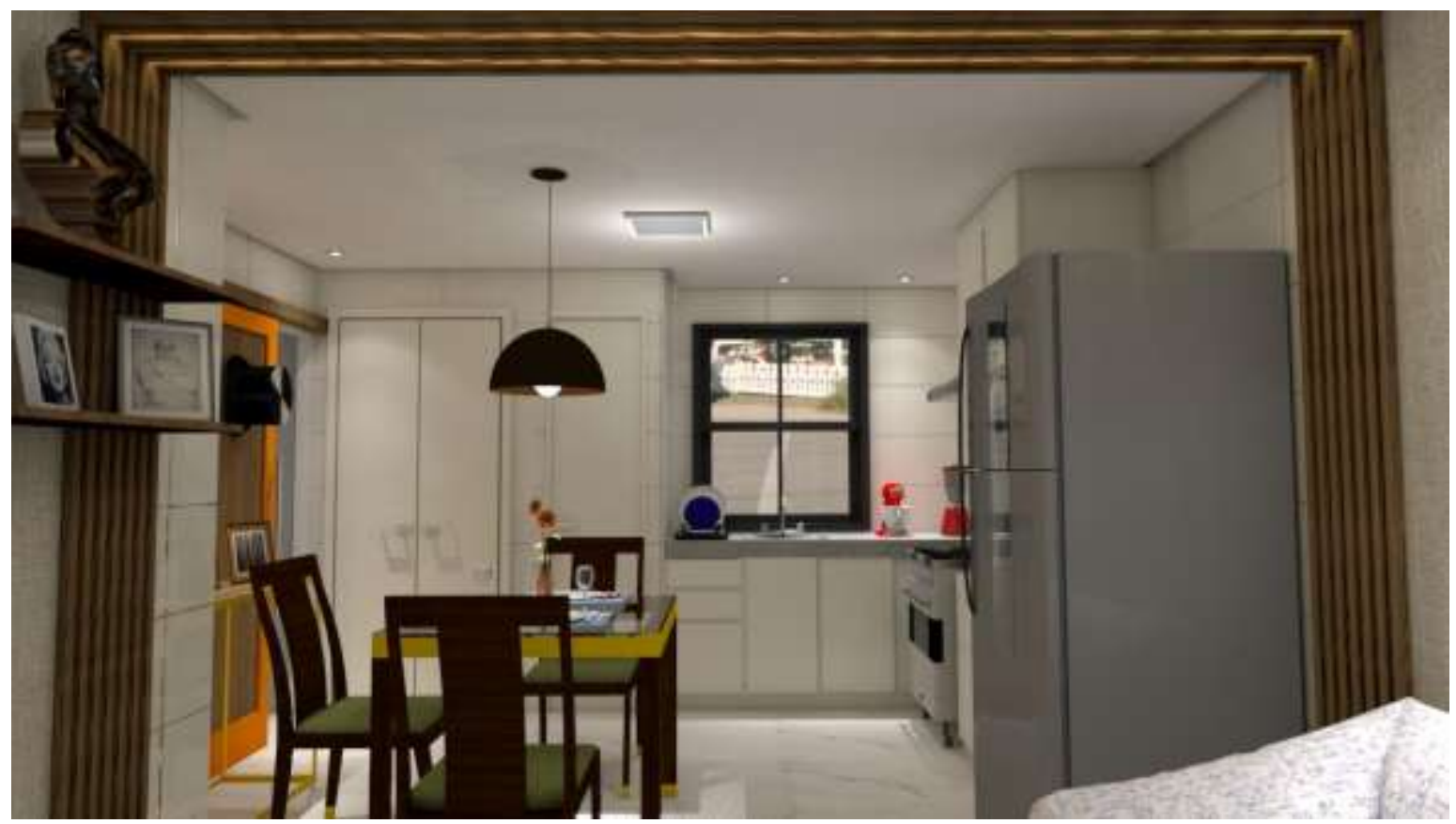

Fonte: Acervo pessoal do autor.

\section{CONCLUSÃO}

Este trabalho teve o escopo de analisar a pesquisa que tem sido feita sobre a influência da cor no cotidiano de um portador da doença de Alzheimer e colocar, com as informações levantadas, os princípios e noções em prática através da criação de sugestões de cores para uma residência para PAs e gerar um maior entendimento e visualização de tais princípios.

Como pesquisas apontam, um espaço bem projetado pode ter impactos positivos na rotina de pacientes (FLEMING, CROOKES, SUM, 2008; MCKERON, 2010; PASCALE, 2002;

SOUSA; MAIA, 2014). Tratando-se mais especificamente de cores, o design pode auxiliar usuários a experimentar sensações e sentimentos desejáveis, além de ajudar na prevenção de depressão e emoções indesejáveis (PASCALE, 2002), pois é sabido que cores tem a capacidade de influenciar o humor das pessoas e que diferentes cores sugerem diferentes sensações. Ao permitir que pacientes vivam em suas próprias residências, com familiares e amigos por perto, estimula-se também o bem-estar dos indivíduos (MCKERON, 2010).

Ademais, devido à doença ocorrer majoritariamente na população idosa, o design pode amparar o paciente nas performances de tarefas básicas que se tornam mais árduas tanto pelo processo de envelhecimento em si como pelo progresso dos estágios da doença (FLEMING, CROOKES, SUM, 2008; PASCALE, 2002). Esse auxílio pode ser oferecido ao tornar elementos dos ambientes mais expressivos, mais reconhecíveis e diferenciáveis elementos estes como as portas de banheiros e dormitórios. O mesmo princípio poder certamente ser utilizado para dificultar o acesso do paciente a espaços e elementos ao empregar neste a mesma coloração de seu entorno e, assim, camuflá-los - como, por exemplo, portas com a mesma coloração de suas paredes.

Apesar de pesquisas apontarem que cores podem impactar pacientes com doença de Alzheimer e suas rotinas, autores informam que as cores por si sós não possuem influência suficiente e o ambiente pode ser melhor destacado e singularizado pelo uso de objetos e 


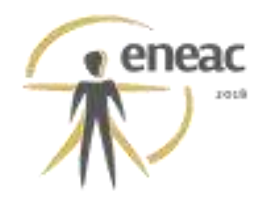

sinalizações formais em vez de simples e unicamente cores (SOUSA, MAIA, 2014; PASCALE 2002). Este argumento deriva principalmente da noção de que, à medida que a doença evolui, pacientes se tornam menos sensíveis a determinadas matizes e tonalidades, dando a certas colorações menos eficácia.

Futuras análises são, então, recomendadas para que exista uma melhor compreensão dos impactos da cor em sua independência, assim como sinalizações, além de uma comparação com o uso destes dois elementos em conjunto. Entretanto, ao tratar-se da influência que cores possuem sobre o emocional humano e nas sensações que geram, não existem pesquisas que comprovem que pacientes com doença de Alzheimer respondem de forma diferente ao restante da população (SOUSA; MAIA, 2014).

\section{REFERÊNCIAS BIBLIOGRÁFICAS}

BEARD, John. "We were older then, we are younger now". 2014. Disponível em: <http://www.who.int/mediacentre/commentaries/ageing/en/>. Acesso em: 11 fev. 2018.

CLARKE, Tom; COSTALL, Alan. The Emotional Connotations of Color: A Qualitative Investigation. Wiley Periodicals, Inc.. Portsmouth, p. 406-410. 2008. Disponível em: <www.interscience. wiley.com>. Acesso em: 17 mar. 2015.

FLEMING, Richard; CROOKES, Patrick A.; SUM, Shima. A review of the empirical literature on the design of physical environments for people with dementia. Austrália: University Of Wollongong, 2008. Disponível em: <http://ro.uow.edu.au/hbspapers/2874/>. Acesso em: 10 mar. 2015.

MCKERON, Maureen Ellen. Architecture, Mind, and Memory: Design for Alzheimer's. 2010. 152 f. Tese (Doutorado) - Curso de Masters Of Architecture, University Of Maryland, College Park, 2010. Disponível em: <https://drum.lib.umd.edu/handle/1903/10771>. Acesso em: 10 mar. 2015.

ORGANIZAÇÃO MUNDIAL DA SAÚDE (Suiça). Global action plan on the public health response to dementia 2017-2025. Geneva: Who Document Production Services, 2017. Disponível em:

<http://www.who.int/mental_health/neurology/dementia/action_plan_2017_2025/en/>. Acesso em: 10 fev. 2018.

PASCALE, Maria Aparecida. ERGONOMIA E ALZHEIMER: A CONTRIBUIÇÃO DOS FATORES AMBIENTAIS COMO RECURSO TERAPÊUTICO NOS CUIDADOS DE IDOSOS PORTADORES DA DEMÊNCIA DO TIPO ALZHEIMER. 2002. 120 f. Dissertação (Mestrado) - Curso de Programa de Pós-graduação em Engenharia de Produção, Universidade Federal de Santa Catarina, Florianópolis, 2002. Disponível em: <https://repositorio.ufsc.br/xmlui/handle/123456789/83716>. Acesso em: 10 mar. 2015.

SOUSA, Isabela Gaspar; MAIA, Ivana Márcia Oliveira. Arquitetura de interiores em ambientes para idosos portadores da doença de Alzheimer. Arq. urb, São Paulo, n. 11, p.192-207, janeiro-julho 2014. Semestral. Disponível em: <http://www.usjt.br/arq.urb/numero- 11/13-isabella-gaspar.pdf>. Acesso em: 10 mar. 2015. 